\title{
Assessment of Student Web Site Usage in a Core Electrical Engineering Course
}

\author{
Ingrid St. Omer \\ Northern Arizona University
}

\begin{abstract}
The increasing interest in on-line courses and distance education suggests the need to evaluate the manner in which students use elements of instructional technology. This paper reviews student usage of various components of a web site developed for a core Electrical Engineering course in semiconductor device physics. Material contained in the web site included the syllabus, the course calendar, assignments and solutions, handouts, abbreviated lecture material, and links to related sites containing java applets and reference material. The analysis is based on a survey of students enrolled in comparable courses at the University of Minnesota and Northern Arizona University. The survey explored usage of individual web pages, links to outside sources, perceptions of computer competency, student demographics, and general computer and Internet usage. An examination of course related email is also discussed. The majority of students felt that using the world-wide web enhanced their learning experience to some extent. The educational impact of on-line course material will be explored in terms of applicant demographics and survey responses. The challenges and opportunities of on-line courses will also be discussed in the context of the survey results.
\end{abstract}

Introduction

The growth of instructional technology in academia, particularly web-based instruction, is evidenced in the expanding number of distance education programs, and the increasing role of the internet both on- and off-campus. In distance education, the primary role of the Internet is as a media for delivering instruction to a remote audience. For on-campus students, the Internet is an opportunity to engage students in their own learning process and augment curricular content. To best utilize the potential of web-based instruction, it is import to determine how students use the Internet and web-based formats. This paper explores student usage of a web site developed for a required Electrical Engineering course in semiconductor device physics implemented at the University of Minnesota (UMN) during the Fall 1999 semester, and at Northern Arizona University (NAU) during the Fall 2000 semester. Students were surveyed regarding their general use of computers, the Internet, and the course web site. Those students who completed the survey received 5 extra credit points by virtue of a cover sheet submitted separately. This encouraged participation and preserved anonymity. Forty UMN students (74\% of the class) and twenty-one NAU students (87.5\% of the class) completed the survey. A copy of the student survey may be found in Appendix A.

Both courses were based on the text Semiconductor Device Fundamentals by Robert F. Pierret and covered the same material. The framework for the course web sites were identical in nature. Each site consisted of a main homepage describing the course logistics (place, time, office hours, etc.), course objectives and textbook information. A link was also included for the respective 
University and departmental homepages. PDF files were used for universal document availability on all of the course pages and a link was included to the free download site for the Acrobat Reader. The Acrobat Reader was also distributed through the campus computing divisions of each university. In general, the web site content was updated on a weekly basis unless otherwise indicated to the students.

The secondary level consisted of the following: Syllabus, Assignments, Handouts, Related Info, and Lecture. The NAU site also contained an additional link to the required semiconductor fabrication laboratory course, EE 462. The Syllabus site contained links to PDF files with general course information such as grading criteria, information about the web site, university policies, and a tentative course calendar. The documents on this site were those handed out to students during the first week of the semester. The Assignments page contained PDF files with individual assignments. Assignments were generally made on a weekly basis with the corresponding solution set posted following the session in which the assignment was due. Found on the Handouts site were, as the name implies, documents distributed in class or during recitation. Example handout materials were additional problems and solutions, summary information, and pertinent information not contained in the textbook. The Related Info site contained external links of supplemental information that might aid students in their understanding of various concepts. Included among these links were two on-line periodic tables, a site detailing the fabrication process, the MIT Semiconductor Subway, Sematech, the Sandia MicroElectroMechanical Systems (MEMS) program, interactive crystal structure applets by Prof. Winston Chan at the University of Iowa Physics Department, and interactive solid-state materials and devices applets by Prof. C. R. Wie's group at SUNY-Buffalo. Much of the material presented in class made use of transparencies prepared using Microsoft PowerPoint. Selected transparencies were converted to PDF files and made available to students through the Lecture section of the web site. Students were instructed that these materials were intended to supplement their own notes and were not a substitute for attendance. Appendix B contains snapshots of the pages developed for the NAU course.

\section{Student Demographics}

In both curriculums, the course under discussion is considered a junior level requirement. At the University of Minnesota, the students were almost evenly split between junior and senior status. However, in the NAU case, approximately $90 \%$ of the students were seniors. Figure 1 illustrates the distribution of student status. Given the racial, ethnic and gender makeup of most Electrical Engineering programs, it is not surprising that the majority of the students completing the survey are white males with an average age of 23. Figures 2 and 3 contain the distributions for gender and racial/ethnic breakdown. The average age of the NAU students was 24 as opposed to an average of 23 for the UMN students. This is not unexpected given that over $90 \%$ of the NAU students were seniors. Approximately $57 \%$ of the students indicated a cumulative GPA of 3.00 or better, equal to the percentage of students expecting a grade of B or higher. All of the NAU students and almost $73 \%$ of the UMN students indicated that they attended a minimum of $75 \%$ of the class. Only $20 \%$ of the UMN students felt they had completed at least $75 \%$ of the assigned work or reading before attending class. In contrast, $81 \%$ of NAU students felt they had accomplished a comparable level of preparation, although this was not generally reflected in their in-class performance. 


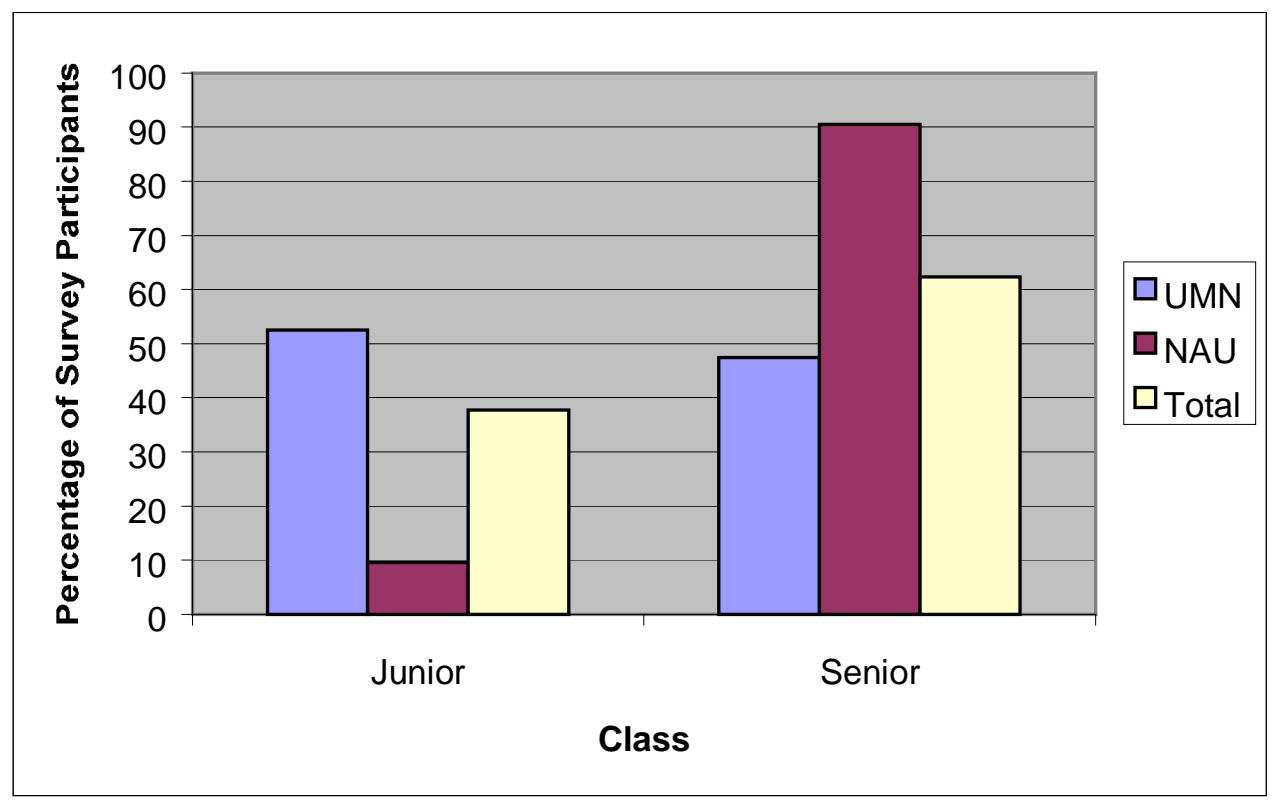

Figure 1. Distribution of student participants by class status.

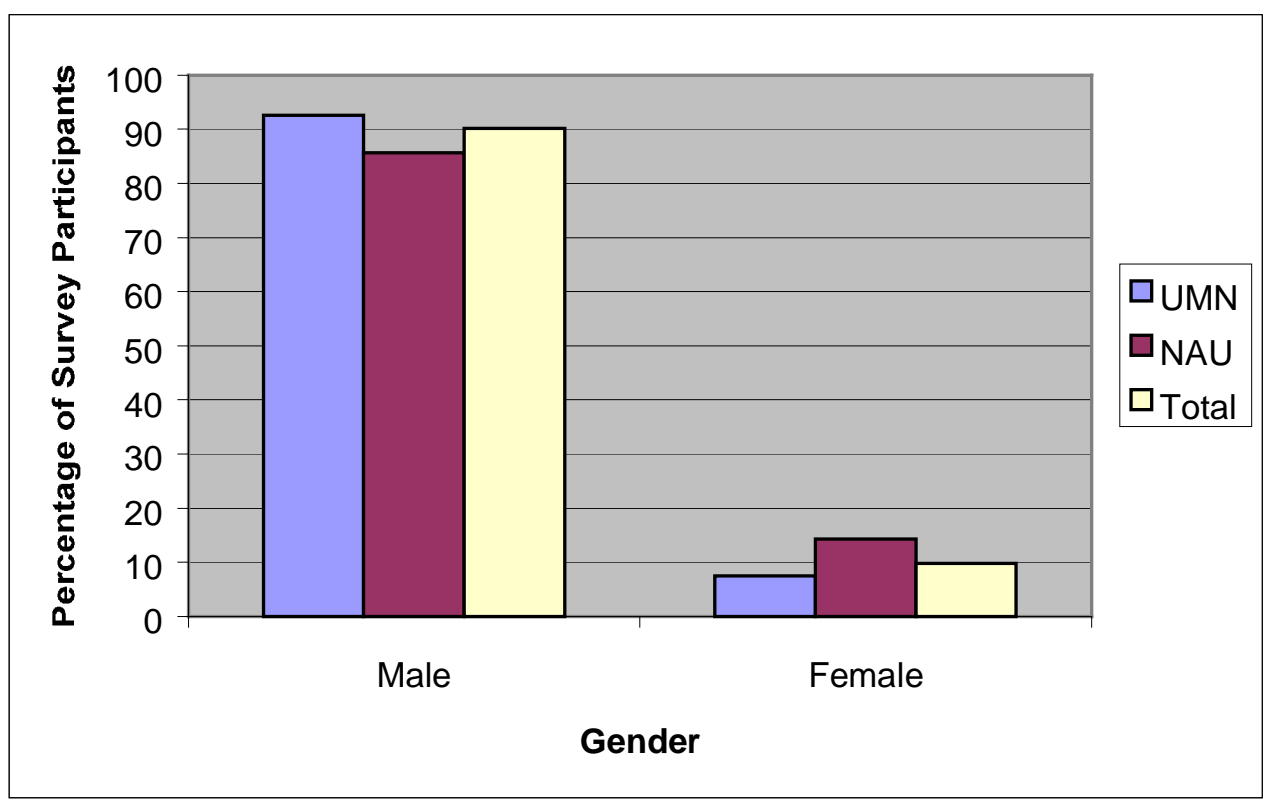

Figure 2. Distribution of student participants by gender. 


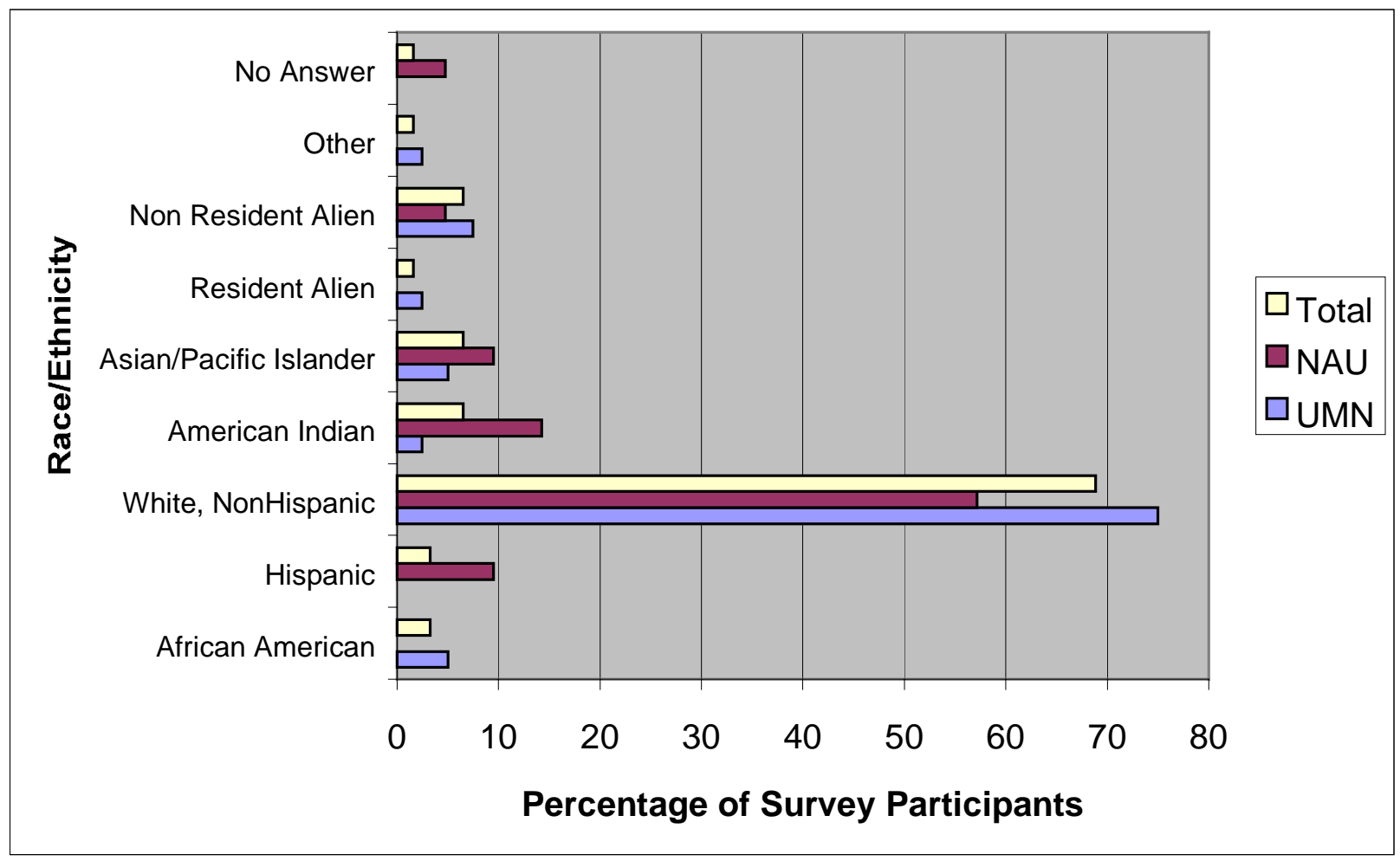

Figure 3. Distribution of student participants by race/ethnicity.

\section{Technology Assessment}

About $50 \%$ of the students used a computer for employment reasons. In comparison, all students indicated academic usage and $98 \%$ indicated personal usage. Ninety five percent of all students use a computer on a daily basis with the remaining students indicating weekly usage. More of the UMN students, $83 \%$ vs. $67 \%$, indicated access to their own personal computer.

Correspondingly, $52 \%$ of NAU students used campus or departmental computer labs in comparison with $40 \%$ of UMN students. Many of the students with their own personal computer also indicated usage of departmental labs. Most students feel confident about their computer skills. Students were asked to rank their computer skills on a scale of 1 to 10; 1 corresponds to excellent, 5 corresponds to fair and 10 corresponds to poor. The distribution of computer skill ranking for all students is contained in Figure 4. All students indicated they use a computer for word processing applications and email. Surprisingly, only $67 \%$ used a computer for games. Figure 5 illustrates the types of applications for which the students used their computers. The majority of students spend three or more hours on-line per week as shown in Figure 6. 


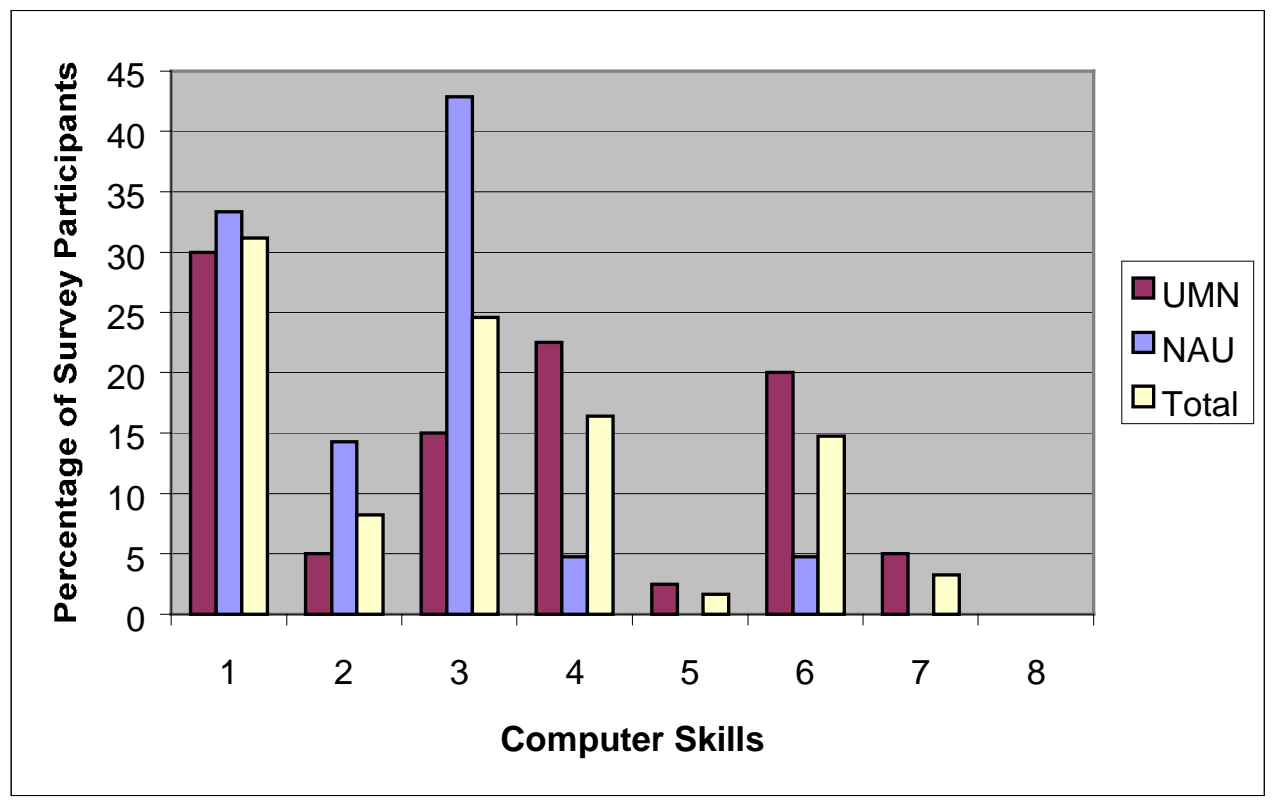

Figure 4. Student self-assessment of computer skills. One corresponds to excellent, 5 corresponds to fair, and 10 poor.

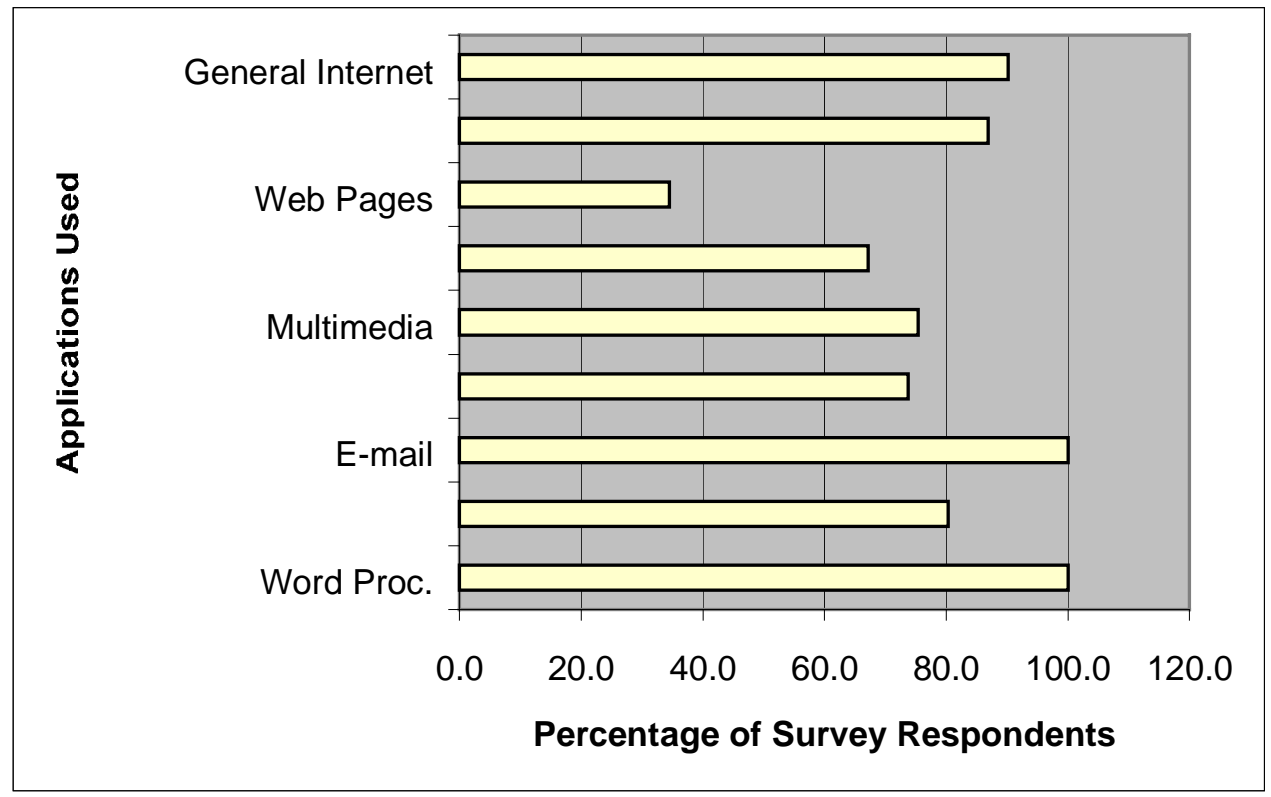

Figure 5. Distribution of student usage of computer applications. 


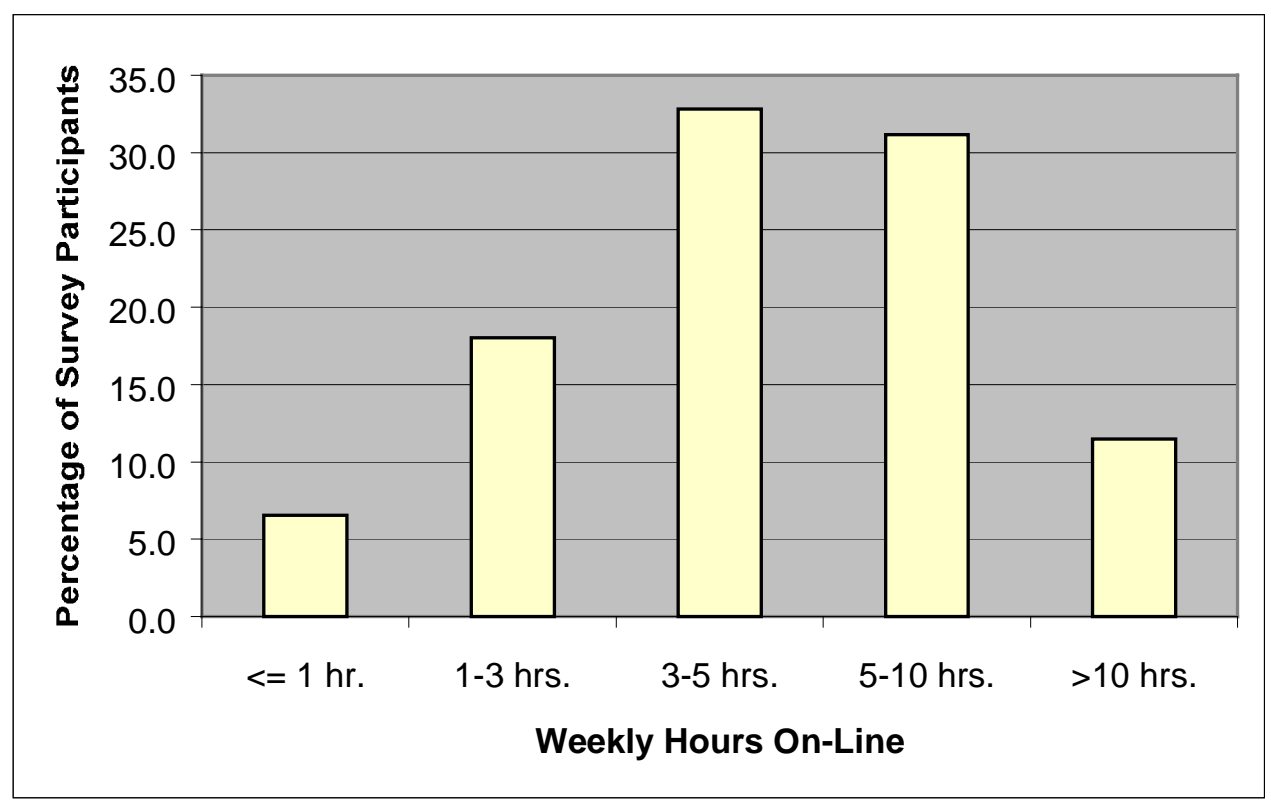

Figure 6. Estimated weekly on-line usage.

Approximately half the students had at least two other courses with web sites. However, $63 \%$ of the students surveyed used the Internet for at least three or more classes. Given that all students surveyed were either juniors or seniors, it was not surprising that $97 \%$ of the students indicated that some of their other classes requiring Internet or web site access were in engineering. There appears to be a correlation between the number of hours spent on-line per week and the number of courses requiring internet or web site access. However, the survey administered does not provide enough information to validate this conclusively.

\section{Course Web Site}

As previously indicated, the course web site was generally updated on a weekly basis. Eighty two percent of the students accessed the web site on a weekly basis, consistent with the availability of new information. Approximately 59\% of the students spent an hour or less on-line per week for this course as shown in Figure 7. Despite the numerous email messages received from students, only about $40 \%$ of the students felt that use of electronic mail had any influence on their learning process although, there was a difference of $10 \%$ between the two institutions. A strong correlation seems to exist between those students who sent email more than once and those students who felt that use of electronic mail had at least a moderate influence on their learning process.

To try to determine which sections of the web site were perceived as most useful, students were asked to indicate which sections they used and the corresponding percentage of time associated with each section. As a follow-up to this summary of their perception, students were also asked a series of questions concerning the content of each section. Approximately $69 \%$ of the students indicated some usage of the Syllabus page, albeit infrequently. The Assignments page received 


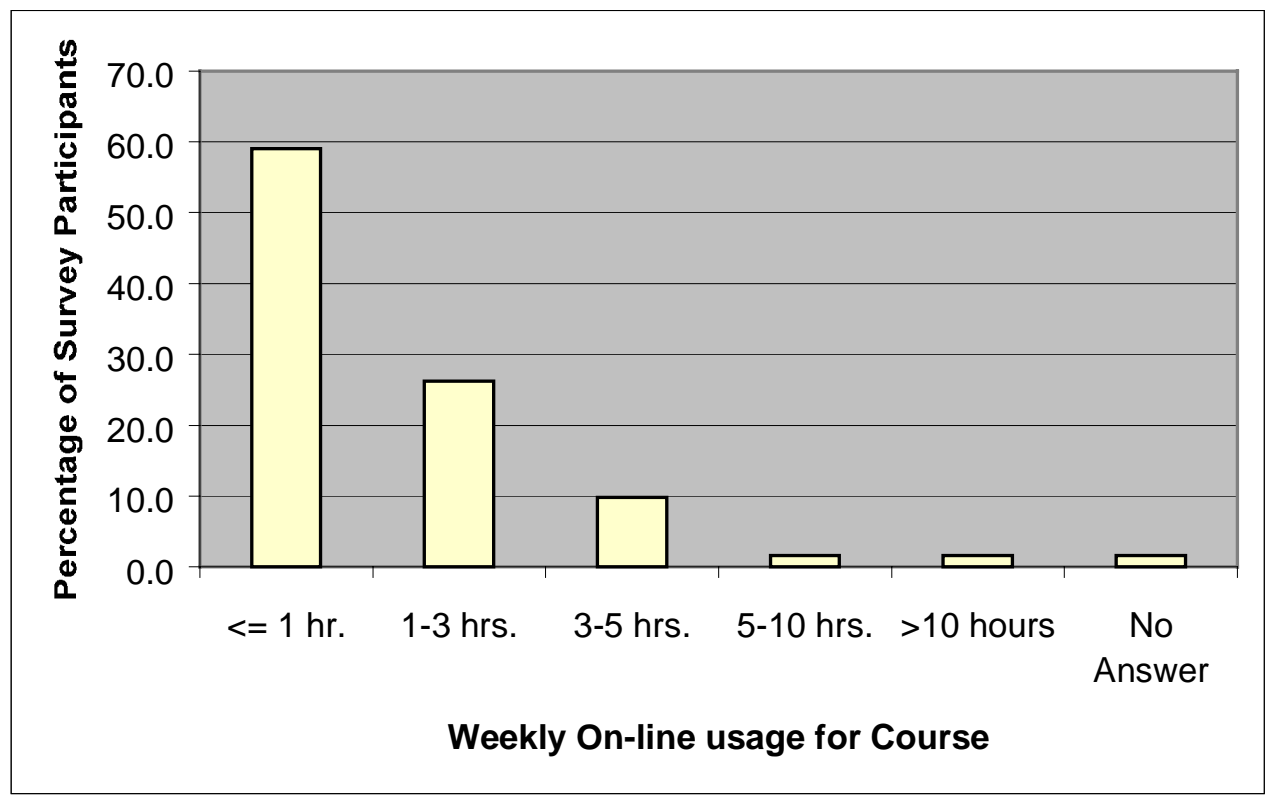

Figure 7. Distribution of weekly on-line usage of the course.

the highest access percentage at $92 \%$. Handouts and Lecture were accessed equally at about $79 \%$. Related Info received the least amount of interest, attracting only $48 \%$ of the students. Table 1 contains a breakdown of the site usage by number of students and the corresponding time percentages indicated. As indicated in the last row of Table 1, several students listed no percentage but indicated they had accessed the site. With the exception of the Syllabus and Lecture, access of the various sites differed by less than $7 \%$ between the two institutions. However, the differences for these two sections of the web site were significant. Eighty two percent of the UMN students accessed the Syllabus page. By comparison, only $43 \%$ of the NAU students accessed this portion of the web site. The Lecture site was accessed by $88 \%$ of the UMN students and only $62 \%$ of the NAU students. It is possible that this discrepancy is based in the significant difference in perception regarding preparation of course assignments and readings but this is not apparent in the survey results.

Seventy nine percent of the students accessing the Assignments page were using both the homework assignments and solutions. The most common comment in the open-ended question regarding the enhancement of student learning by the web site was the benefit of having easily available problems and solutions.

Table 1 Summary of Course Web Site Section Access for all Students

\begin{tabular}{|l|c|c|c|c|c|}
\hline Site Sections & Syllabus & Assignments & Handouts & Related Info & Lecture \\
\hline $1-25 \%$ & 32 & 4 & 34 & 18 & 21 \\
\hline $26-50 \%$ & 4 & 20 & 2 & 4 & 16 \\
\hline $51-75 \%$ & 0 & 8 & 0 & 0 & 1 \\
\hline $76-100 \%$ & 1 & 11 & 2 & 1 & 1 \\
\hline No Percentage & 5 & 13 & 10 & 6 & 9 \\
\hline Total Number & 42 & 56 & 48 & 29 & 48 \\
\hline
\end{tabular}


Forty eight percent of all students accessing the Handouts page used all the available elements. Approximately 5\% of the NAU students and 13\% of the UMN students used only the recitation problems and solutions. Students at the University of Minnesota enroll in a two-hour recitation section at the time they enroll in the class. The one-hour recitation section offered to the NAU students was voluntary and based on student schedules. The lack of official sanction associated with the NAU recitation may account for this difference.

Students were asked how often they had accessed the Lecture portion of the web site. Figure 8 contains the distribution of the responses. The majority of students accessed the Lecture page between 1 and 5 times during the semester. This suggests that the Lecture summaries were generally used to assist students in preparing for the two regular exams and the final, as well as any missed lecture material. Only about $16 \%$ of the students accessed the page on a fairly regular basis (> 10 times). Of those students utilizing the lecture summaries, roughly $75 \%$ found them at least moderately useful. Although a lower percentage of NAU students accessed the Lecture page, they placed a greater value on them as indicated in Figure 9.

The low access frequency for the Related Info page was disappointing and consistent between the two institutions. This is unfortunate given the potential appeal of these links to a wide variety of learning styles. Students were shown the contents of the links during the initial week of class and the links were referenced periodically during the semester. Despite these efforts, few students ventured into the additional information. Several of the students commented that they should have investigated these links and suggested that I use them in class during lecture. Figure 10 shows the access distribution for these links.

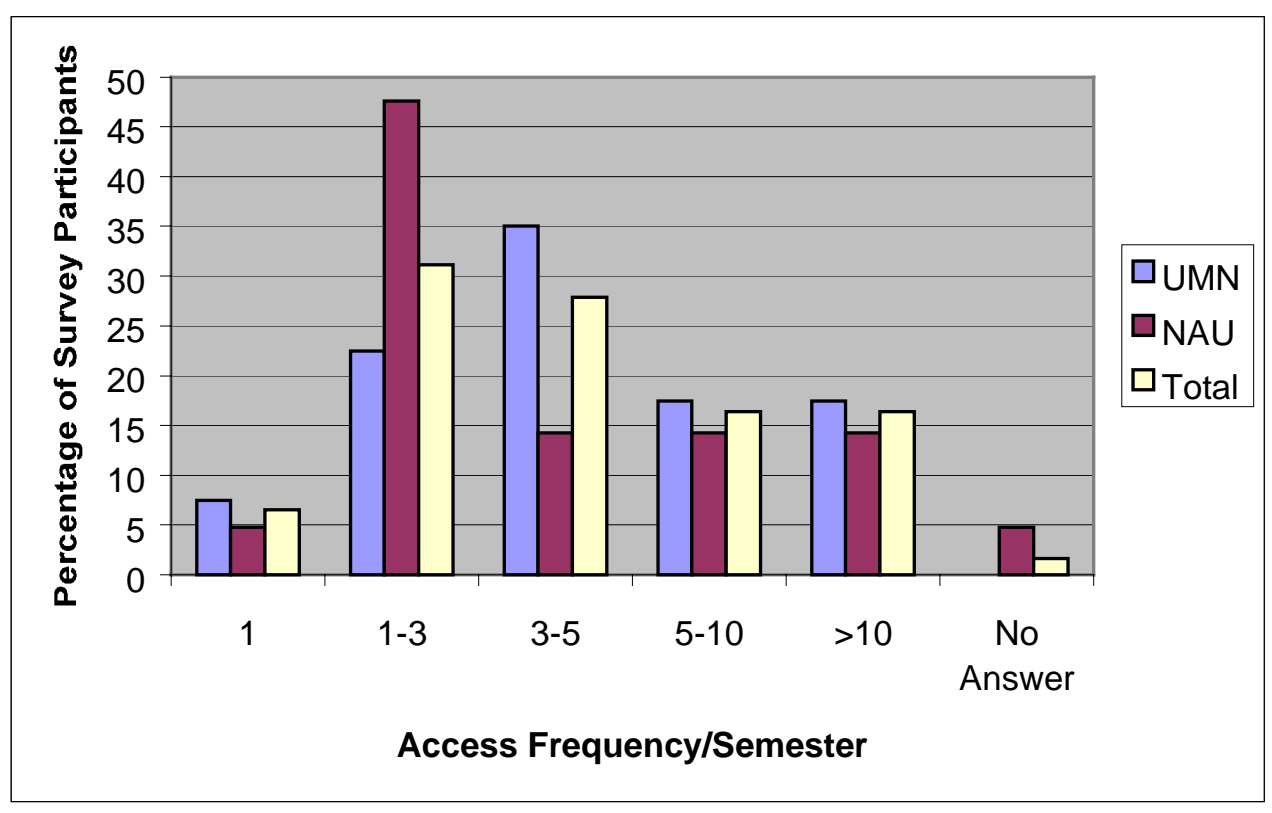

Figure 8. Access frequency for Lecture portion of the course web site. 


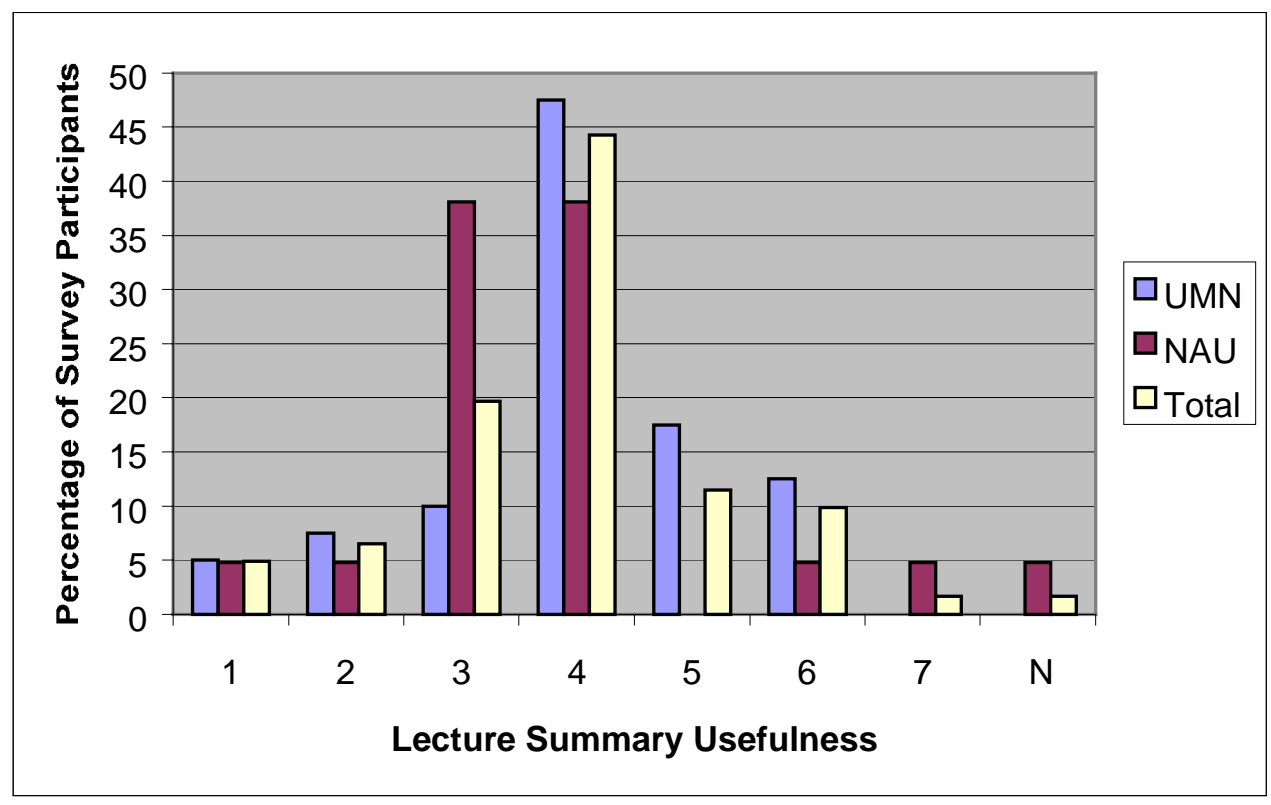

Figure 9. Student ranking of Lecture Summary usefulness. One is very helpful, 4 is moderately helpful and 7 is no help at all.

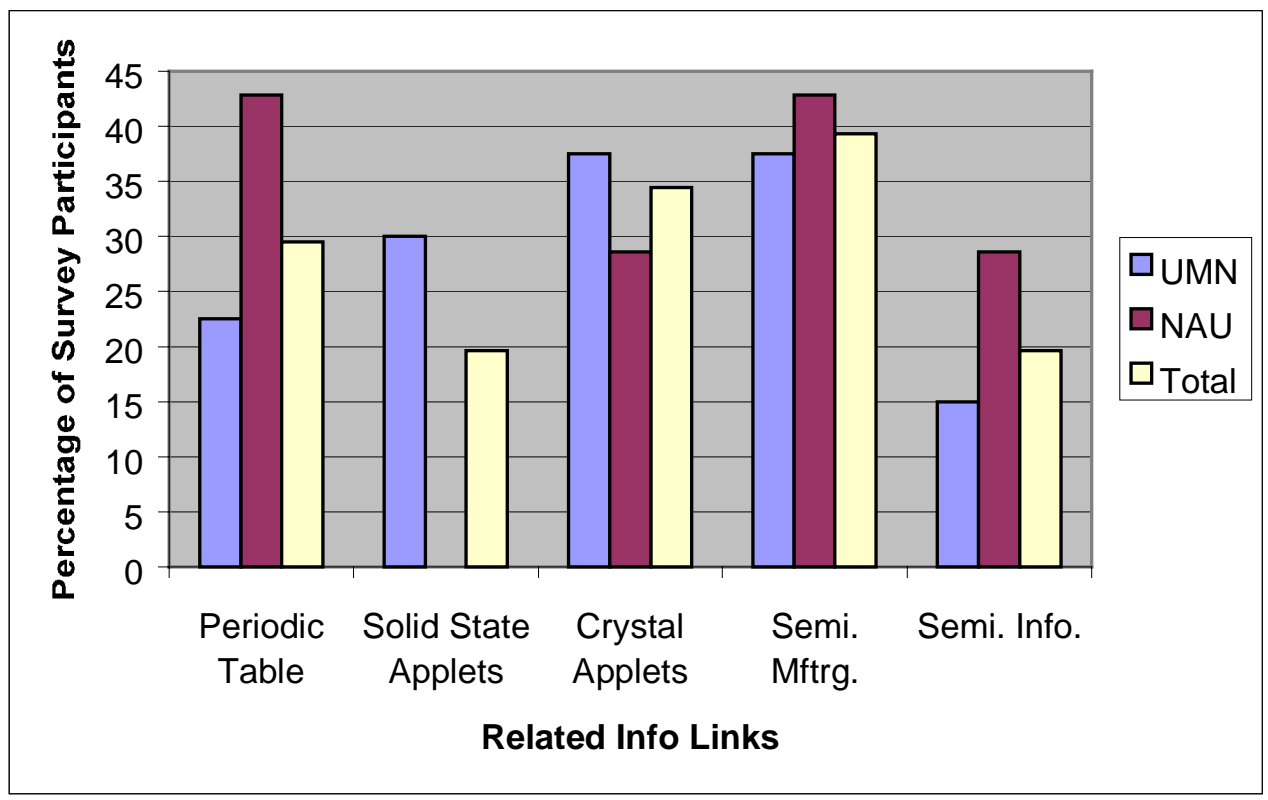

Figure 10. Distribution of student usage of Related Info links. 
The final series of questions dealt with the influence of the course on the learning process and their computing skills, as well as interest in future participation in courses involving instructional technology. Students were asked to rate the influence of the world-wide web on their learning experience on a scale of 1 to 7; one corresponds to no influence at all, 4 moderately influential, and 7 greatly influential. Approximately $61 \%$ of all students found the web to be at least moderately influential. This value differed by less that $1 \%$ between institutions. Figure 11 illustrates these survey results. Although the students felt the web was a positive influence on their learning experience, on average slightly less students, only $59 \%$, felt that the use of technology assisted them in getting a higher grade for the course. In this case, 1 corresponds to a great deal of assistance, 4 moderate assistance, and 7 no assistance at all. Here again, significant differences existed between the institutions. As shown in Figure 12, approximately $70 \%$ of the UMN students felt that it improved their grade potential while only $38 \%$ of the NAU students believed in the improvement potential. The question of preparation could possible be linked to this discrepancy. If the student felt that the web was providing information as opposed to reinforcing the material, the perceived improvement in grade might vary significantly. Almost all the students surveyed indicated little or no change in their computer skills as a result of the course. Given that most students felt the web was a positive influence on their learning experience, it was not surprising that almost all students were interested in taking another course using technology as part of the curriculum. Figure 13 illustrates these survey results.

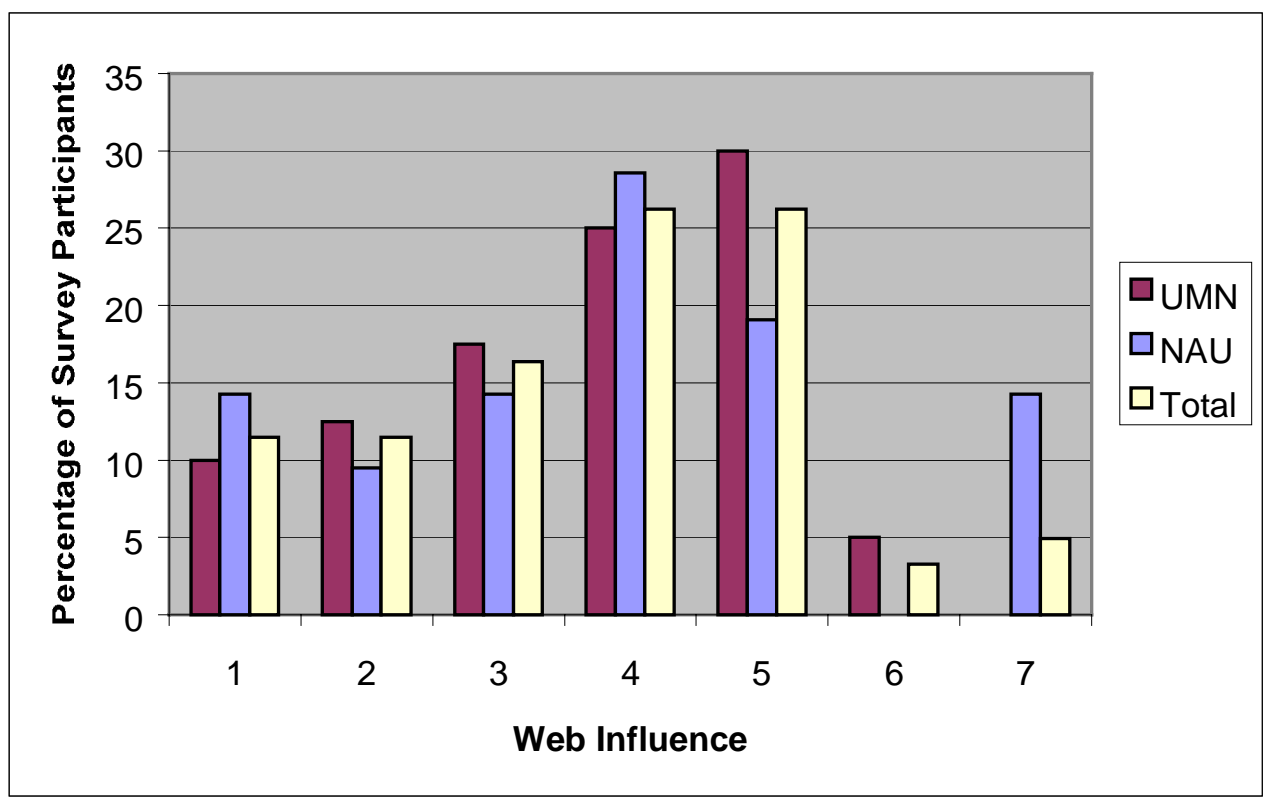

Figure 11. Influence of the world-wide web on the learning experience. On a scale of 1 to 7; one corresponds to no influence at all, 4 moderately influential, and 7 greatly influential. 


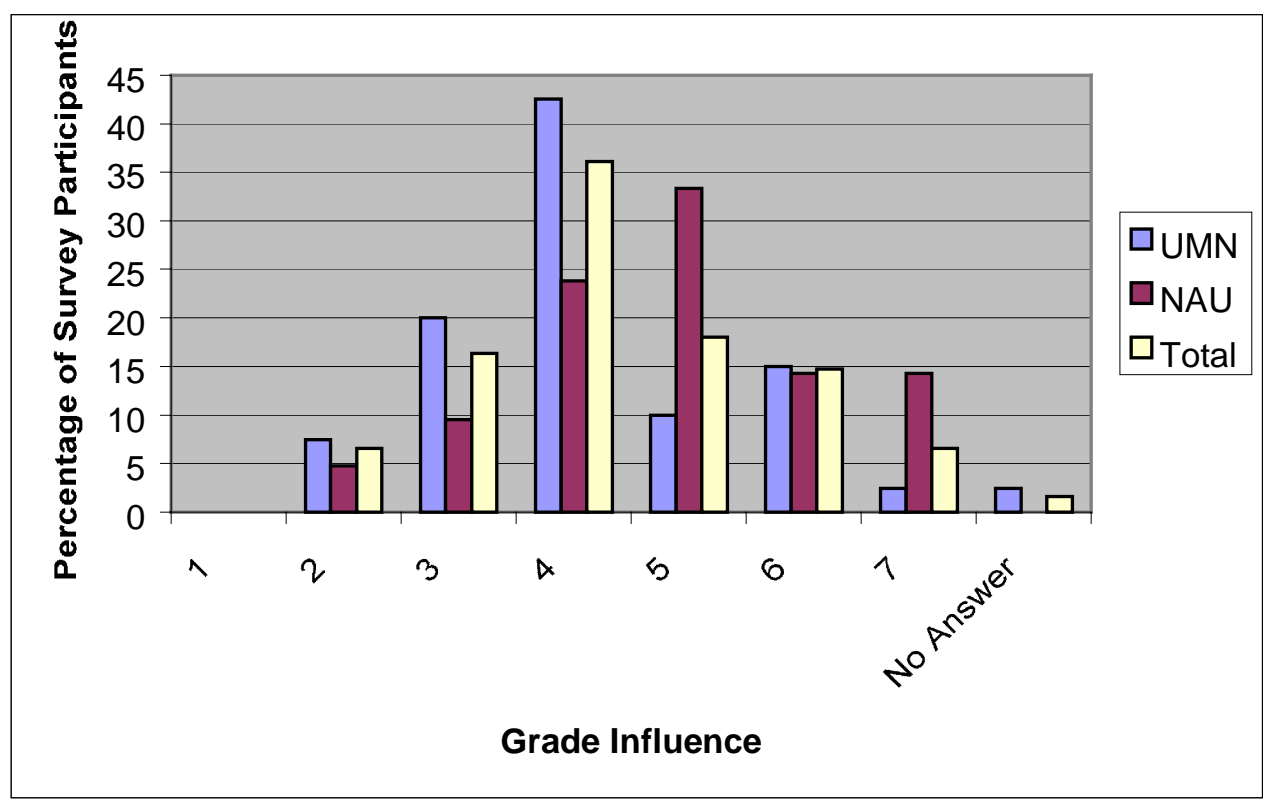

Figure 12. Influence of instructional technology on course grade. In this case, 1 corresponds to a great deal of assistance, 4 moderate assistance, and 7 no assistance at all.

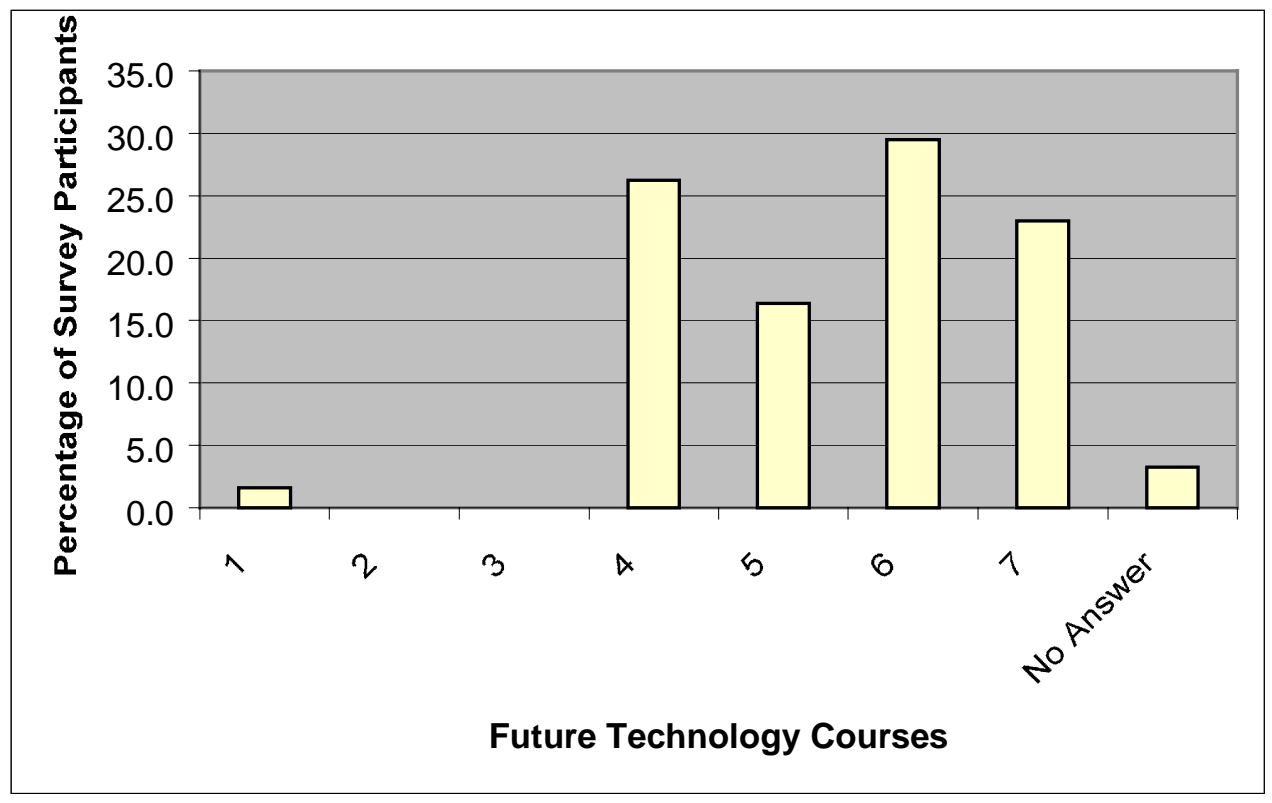

Figure 13. Student interest in courses incorporating instructional technology. On a scale of 1 to 7; one corresponds to no interest at all, 4 moderately interested, and 7 greatly interested. 


\section{Conclusion}

Web-based instruction is appealing for its potential to improve the learning experience for both traditional and place-bound students. To achieve this potential, a database of knowledge must be developed to guide the implementation of effective and efficient course materials. An analysis of the survey results from students enrolled in a required course in semiconductor physics at the University of Minnesota and Northern Arizona University illustrates both the promises and the pitfalls of this technology. Although most students felt they had the necessary technical skills and spent 3-10 hours/week on-line, use of the web site seemed to focus on homework solutions prior to an exam. The majority of students felt that using the web had a positive influence on their learning experience, yet many failed to fully utilize the complete scope of web site materials. A limited number of students took advantage of material designed to enhance conceptual understanding such as the java applets. However, upon completion of the survey, several students examined these links and indicated belated appeal. A slightly larger pool of students investigated the links providing information on semiconductor manufacturing and industry information. More vigorous incorporation of the web materials into topical classroom discussions may increase the utilization of the value-added components. Almost all students expressed interest in increased technology in the curriculum, yet the perceived benefit of the web experience appeared to be somewhat dependent on an individual student's preparation for the course.

\section{INGRID ST. OMER}

Ingrid St. Omer is currently an Assistant Professor and Director of the Advanced Microelectronics Laboratory at Northern Arizona University. Prior to earning her doctorate, she worked in industry on the design of Application Specific Integrated Circuits. After attaining the rank of Senior Engineer and Engineering Supervisor, she attended the University of Missouri-Columbia (MU) to pursue a Ph.D. in Electrical Engineering. Upon completion of the Ph.D. degree, she served as a Visiting Assistant Professor in the MU Department of Electrical Engineering, and then as a Research Associate and President's Postdoctoral Fellow at the University of Minnesota. 


\section{Appendix A: Student Survey}

\section{EE 461 Technology Survey}

My Class is:

Freshman Sophomore Junior Senior Graduate Other

Sex:

Male Female

Racial/Ethnic Origin:

African American Hispanic White, Non-Hispanic American Indian

Asian/Pacific Islander Resident Alien $\quad$ Non-resident Alien

Age:

The grade I expect to receive is:
B
C D
F $\quad$ S U

Percentage of classes I attended:
$0-25 \%$
$25-50 \%$
$50-75 \%$
$75-90 \%$
$90-100 \%$
Not applicable

Percentage of classes for which I completed the assigned work or reading before class:
$0-25 \%$
$25-50 \%$
$50-75 \%$
75-90\%
90-100\%
Not applicable

My cumulative GPA is in the range:

$\begin{array}{cllll}\geq 3.5 & 3.49-3.00 & 2.99-2.50 & 2.49-2.00 & 1.99-1.50 \\ 1.49-1.00 & <1.00 & & & \end{array}$

I use a computer for

$\square$ academic $\square$ personal $\square$ employment

On a scale of 1 to 10 , I would rate my computer skills as:

$\begin{array}{lllllll}1 & 3 & 5 & & 7 & 10 & \\ \text { excellent } & & & \text { fair } & & & \text { poor }\end{array}$

I use a computer:
daily
weekly
monthly
not at all

I use a computer for (check all that apply):

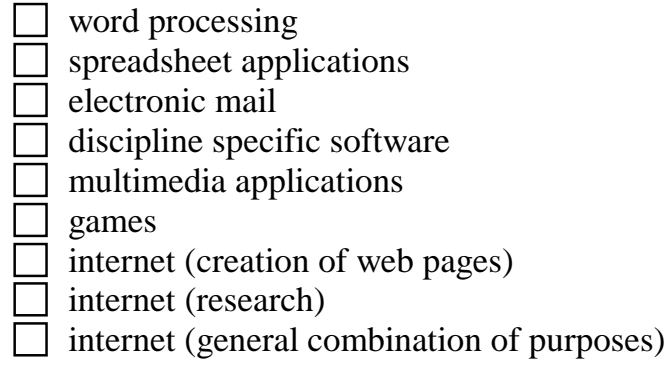

The computer I generally used for this class was:

$\square$ my personal computer

$\square$ a departmental lab computer

a campus lab computer

$\square$ other

Proceedings of the 2001 American Society for Engineering Education Annual Conference \& Exposition

Copyright $\odot$ (2001, American Society for Engineering Education 
How many hours a week do you spend on-line?
$\leq 1$ hour
1-3 hours
3-5 hours
5-10 hours

$>10$ hours

I currently use the internet for

other classes.

one two three four five or more

I use a class web site for other classes.
one
two
three
four
five or more

The classes which require internet or web site access are (check all that apply):

$\square$ engineering $\square$ physical sciences $\square$ math $\quad \square$ fine arts $\square$ computer engr./science

$\square$ other

How often did you access the web page for this course?

once daily weekly monthly not all

How many hours a week did you spend on-line for this course?
$\leq 1$ hour
$1-3$ hours
3-5 hours
5-10 hours
$>10$ hours

Use of electronic mail influenced my learning of the course content.
1
not at all
2
3
4 moderately
6
7
a great deal

I used electronic mail for general/homework questions

once daily weekly monthly not all

Indicate which sections and the corresponding percentage used (if any) for the following portions of the course web page:

$\square$ Syllabus and course calendar
$\square$ Assignments
$\square$ Handouts
$\square$ Related Information
$\square$ Lecture

I used the Assignments web page for:

homework assignments homework solutions both assignments \& solutions

never used it

I used the Handouts page for:

recitation problems test results handouts all of the above

I used the following sections of the Related Information page (check all that apply):

$\begin{array}{ll}\square \text { Periodic Table } & \square \text { Semiconductor Manufacturing } \\ \square \text { Java Applets } & \square \text { Semiconductor Industry Information } \\ \square \text { Crystal Structures info } & \square \text { Other }\end{array}$

I accessed the Lecture section of the web site:

once $\quad 1-3$ times $\quad 3-5$ times $5-10$ times more than 10 times

I found the supplemental lecture summaries
1
2
3
$4 \quad 5$
5
6
7
very useful
moderately useful
not at all useful

Proceedings of the 2001 American Society for Engineering Education Annual Conference \& Exposition

Copyright $\odot$ 2001, American Society for Engineering Education 
Using the world-wide web influenced my learning of the course content

$\begin{array}{cllllrlll}1 & 2 & 3 & 4 & 5 & 6 & 7 & \text { a great deal } \\ \text { not at all } & & & & & \text { moderately } & & & \end{array}$

How much did the use of technology assist you in getting a higher grade for this course?

$\begin{array}{cccccccc}1 & 2 & 3 & 4 & 5 & 6 & 7 & \text { not at all }\end{array}$

My computer experience prior to this course was:

$\begin{array}{llllll}1 & 2 & 3 & 4 & 5 & \\ \text { Beginner } & & \text { Average } & & \end{array}$

My computer experience as a result of this course was:

$\begin{array}{cccccc}\begin{array}{llll}1 \\ \text { Beginner }\end{array} & 2 & 3 & 5 & \text { Expert }\end{array}$

Would you be interested in taking another course that uses technology as part of the curriculum?

$\begin{array}{ccccccccc}1 & 2 & 3 & 4 & 5 & 6 & 7 & \text { a great deal } \\ \text { not at all } & & & & & \text { moderately } & & & \end{array}$

Is there anything that would have made using the internet or other technology in your class easier?

In what ways did the use of the web site or other technology enhance your learning? 


\section{Appendix B: Web Site Design}

Main Page

SiEE 461 - Microsoft Internet Explorer

\begin{tabular}{|c|c|c|c|c|c|c|c|c|c|c|c|c|c|}
\hline File É dit & View Fav & orites & Iools & Help & & & & & & & & & 为 \\
\hline $\begin{array}{c}4 \\
\text { Back }\end{array}$ & $\begin{array}{c}\Rightarrow \\
\text { Forward }\end{array}$ & Y & $\underset{\text { Stop }}{\otimes}$ & Refresh & Home & Search & Favorites & $\begin{array}{c}3 \\
\text { History }\end{array}$ & Mail & Print & $\frac{\text { EN }}{\text { Edit }}$ & RealGuide & \\
\hline Address & F:'published & index & chtml & & & & & & & & & $\nabla \curvearrowright G_{0}$ & Links \\
\hline
\end{tabular}

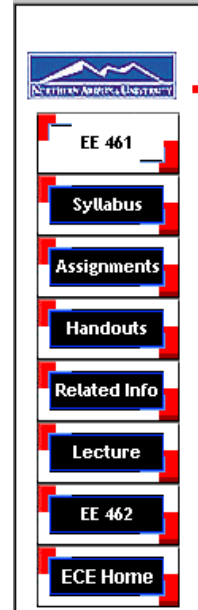

\section{EE 461}

Fall Semester 2000

EE 461: Semiconductor Devices

Lecture: MWF 1:50-2:40 pm

Room: Bldg. 69, Rm. 206

Recitation: Friday 8:00-9:00 am Bldg. 69, Rm. 206

Instructor: Dr. Ingrid St. Omer

Office: Engineering (Bldg. 69), Rm. 155

Phone: 523-4809

Email: Ingrid.StOmer@nau.edu

Office Hours: Wednesday 9:00-11:00 am

Thursday 10:00 am-12:00 pm

Or by appointment

Course Objective:

This course is designed to provide an introduction to the physical electronics of semiconductors. This overview will include energy band theory, material doping, and carrier behavior and transport. These concepts will then be extended

\begin{tabular}{|c|c|c|}
\hline E] Done & & 밐 My Computer \\
\hline SStart $\square$ jan-CRT & 㭗NetObjects Fusion - 4... EjEE 461 - Microsof... & (1) 啫回面 $1: 22 \mathrm{PM}$ \\
\hline
\end{tabular}




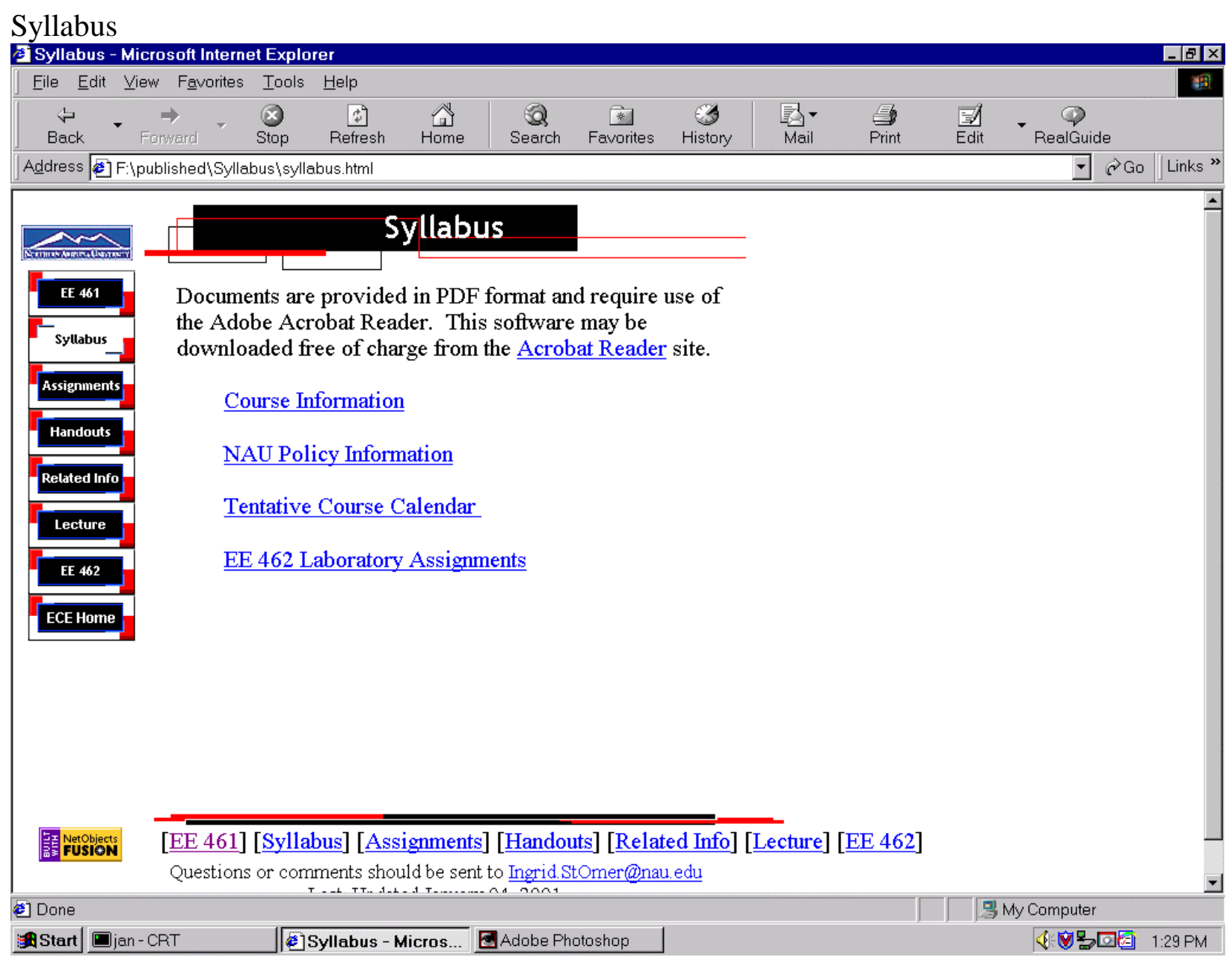




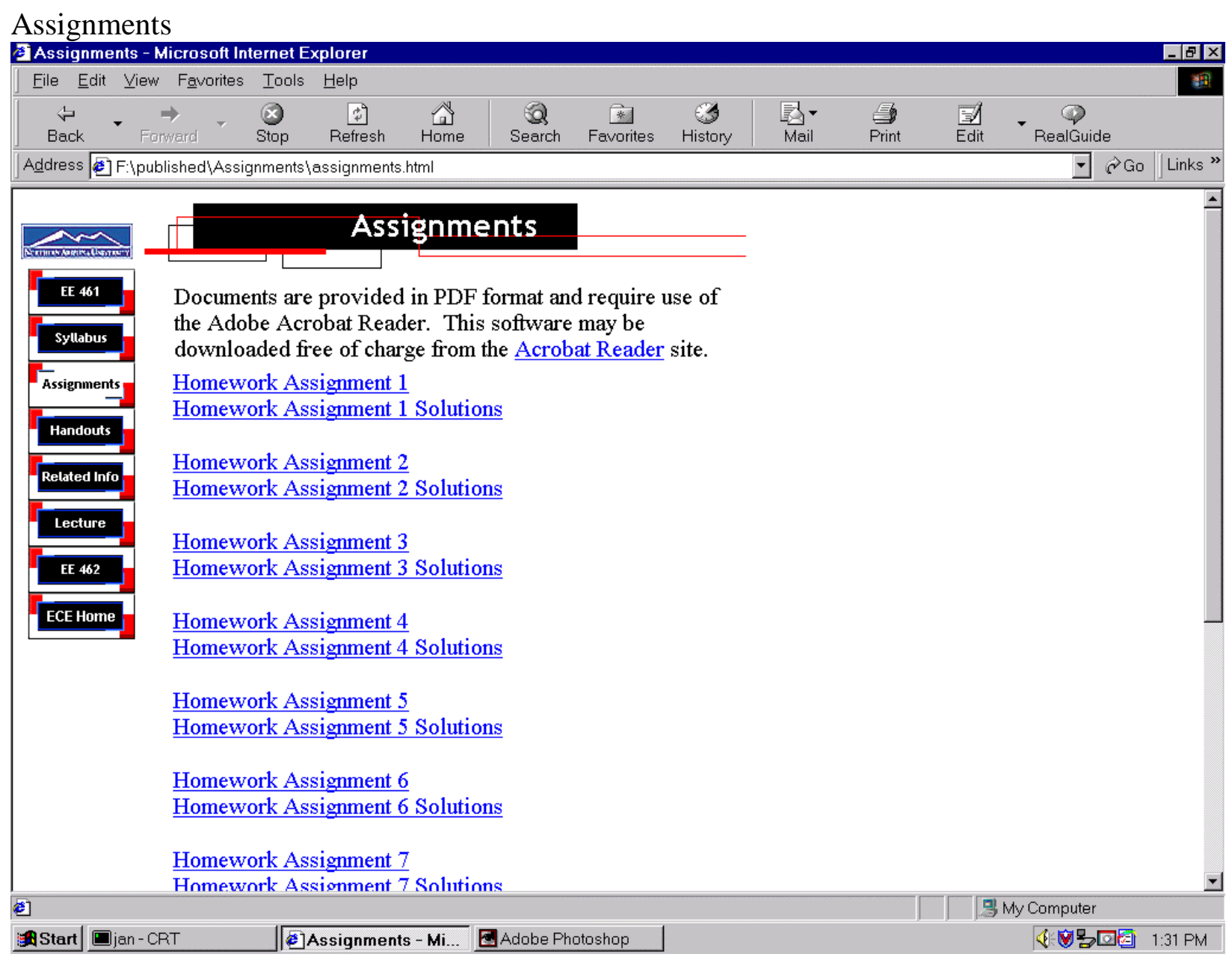




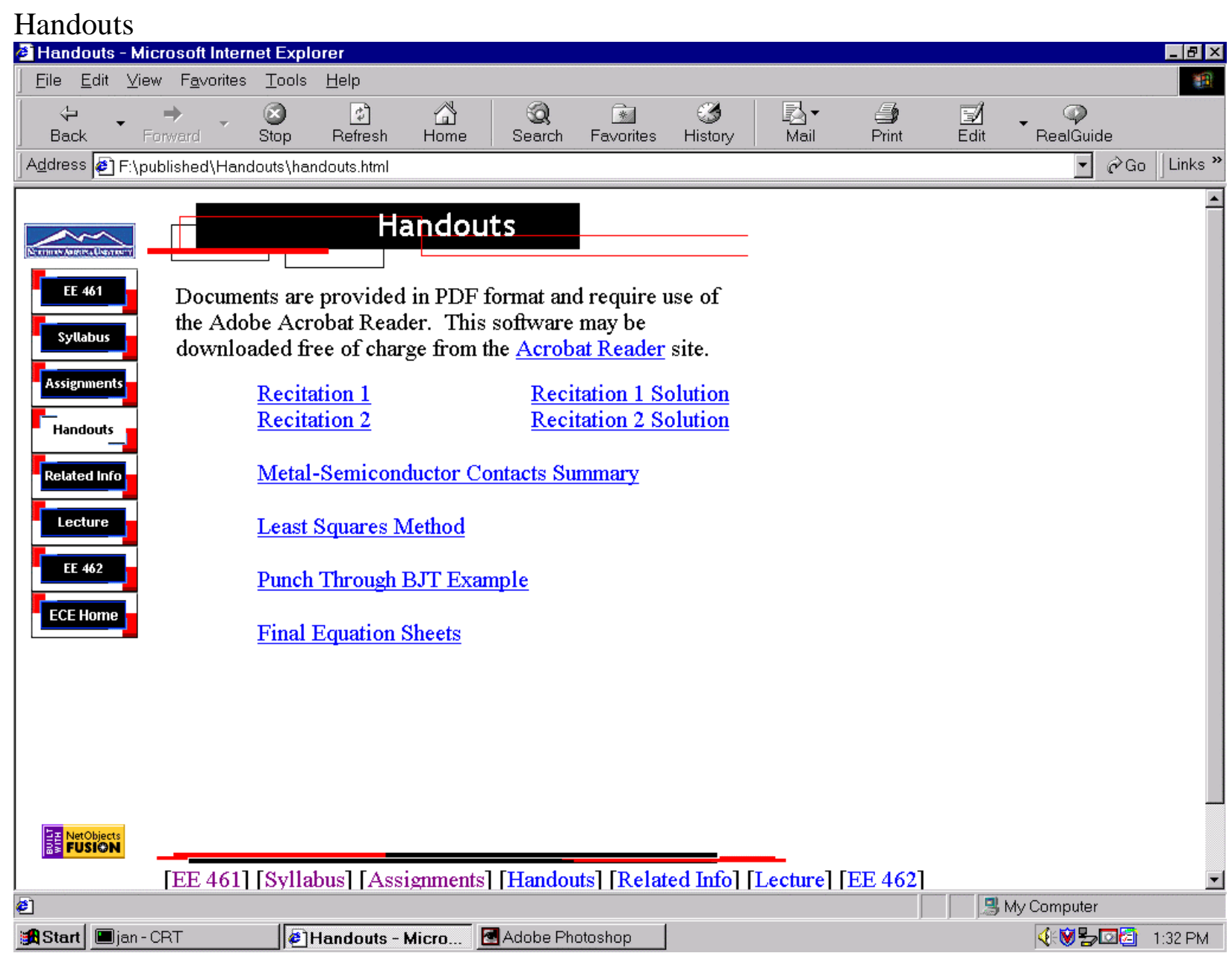




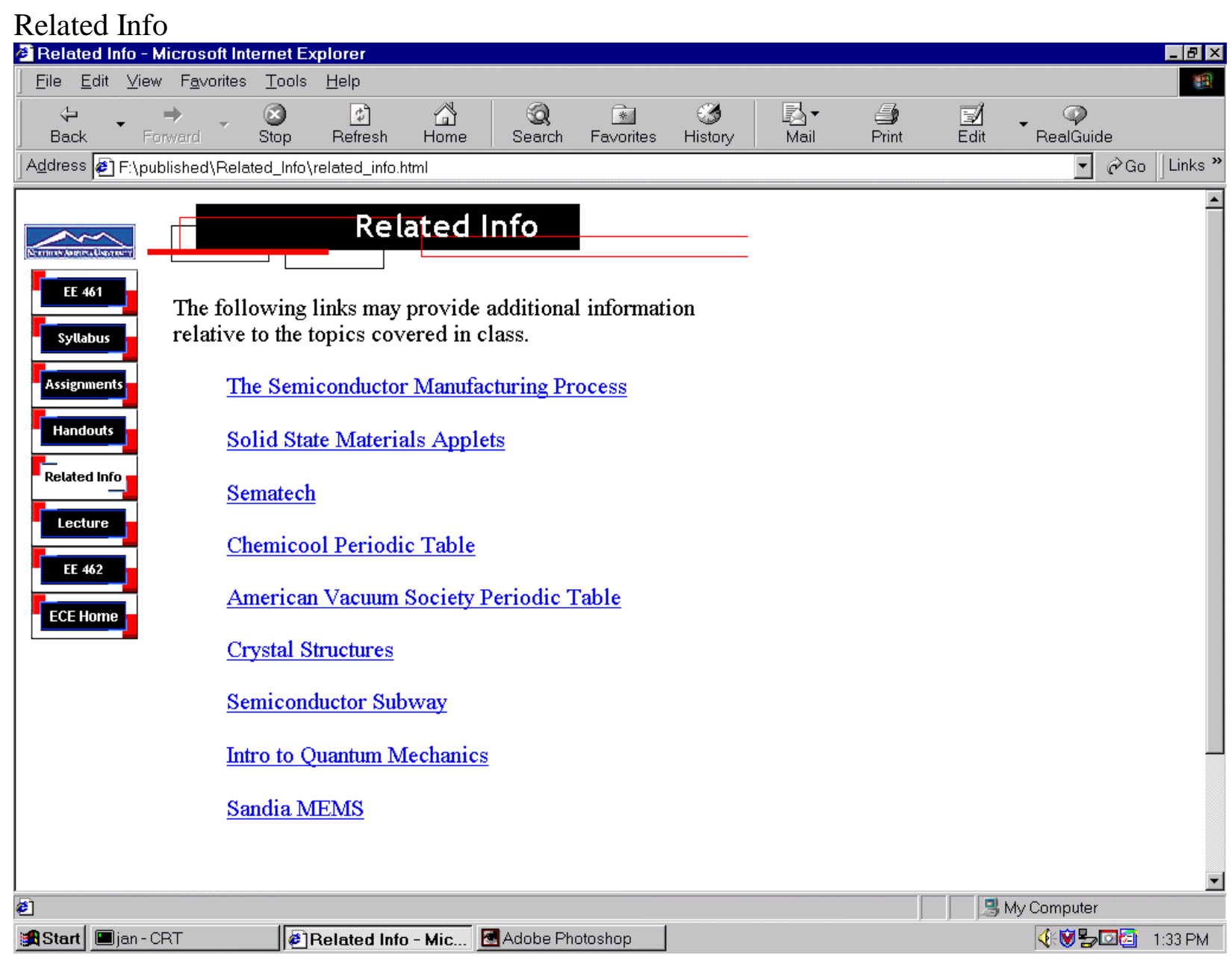




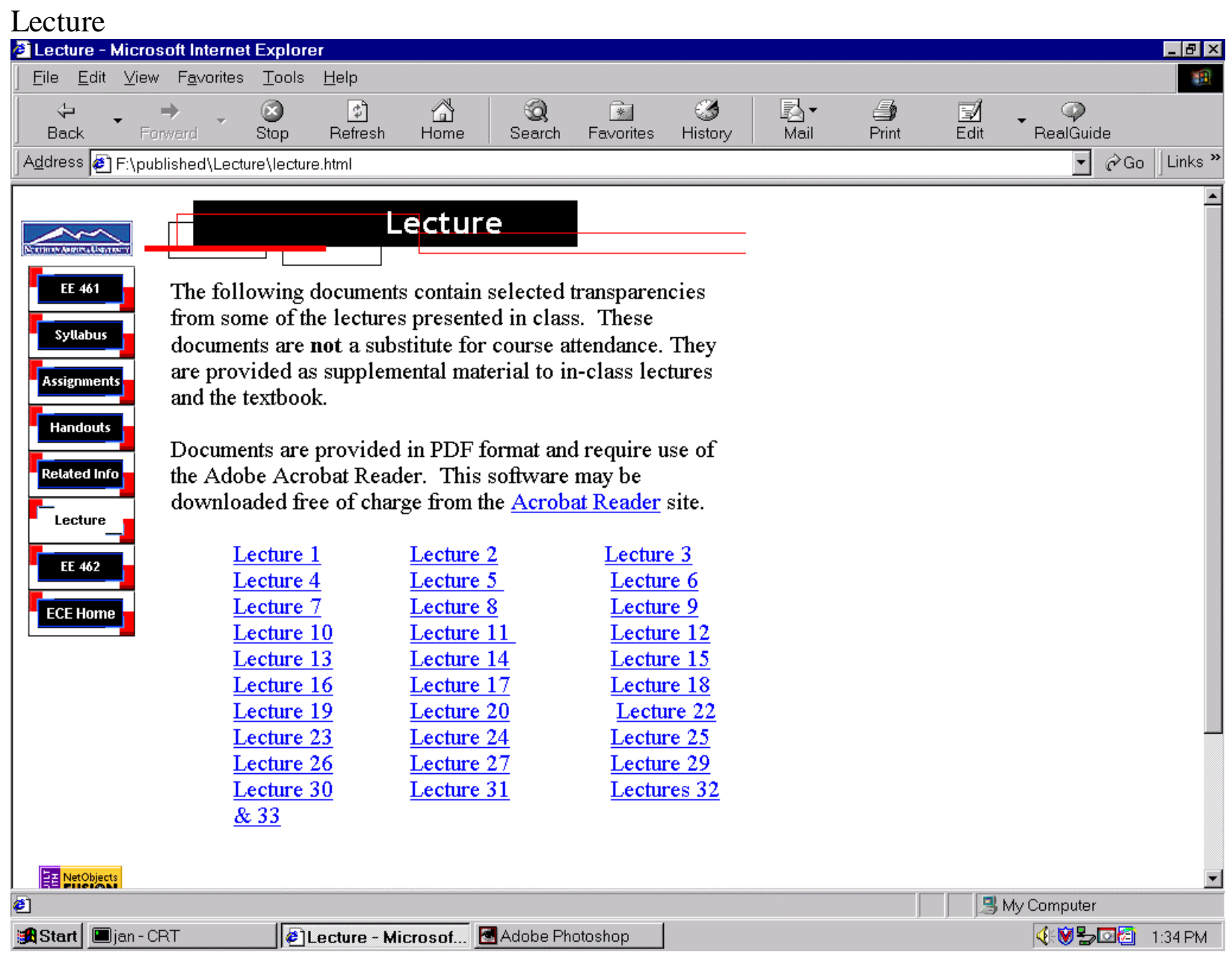

